University of Nebraska - Lincoln

DigitalCommons@University of Nebraska - Lincoln

Faculty Papers and Publications in Animal

Science

Animal Science Department

September 2006

\title{
Microarray profiling of skeletal muscle sarcoplasmic reticulum proteins
}

Jospeh S. Schulz

University of Nebraska-Lincoln

Nathan Palmer

U.S. Department of Agriculture, Agricultural Research Service, Lincoln, NE

Jon Steckelberg

University of Nebraska-Lincoln

Steven J. Jones

University of Nebraska-Lincoln, sjones1@unl.edu

Michael G. Zeece

University of Nebraska-Lincoln, mzeece1@unl.edu

Follow this and additional works at: https://digitalcommons.unl.edu/animalscifacpub

Part of the Animal Sciences Commons

Schulz, Jospeh S.; Palmer, Nathan ; Steckelberg, Jon; Jones, Steven J.; and Zeece, Michael G., "Microarray profiling of skeletal muscle sarcoplasmic reticulum proteins" (2006). Faculty Papers and Publications in Animal Science. 109.

https://digitalcommons.unl.edu/animalscifacpub/109

This Article is brought to you for free and open access by the Animal Science Department at DigitalCommons@University of Nebraska - Lincoln. It has been accepted for inclusion in Faculty Papers and Publications in Animal Science by an authorized administrator of DigitalCommons@University of Nebraska - Lincoln. 


\title{
Microarray profiling of skeletal muscle sarcoplasmic reticulum proteins
}

\author{
Joseph S. Schulz ${ }^{\mathrm{a}}$, Nathan Palmer ${ }^{\mathrm{b}}$, Jon Steckelberg ${ }^{\mathrm{c}}$, Steven J. Jones ${ }^{\mathrm{a}}$, Michael G. Zeece ${ }^{\mathrm{c}, *}$ \\ a Department of Animal Science, University of Nebraska, Lincoln, NE 68583, USA \\ ${ }^{\mathrm{b}}$ U.S. Department of Agriculture, Agricultural Research Service, Lincoln, NE 68583, USA \\ c 354 FIC, Department of Food Science, University of Nebraska, Lincoln, NE 68583, USA
}

Received 8 November 2005; received in revised form 19 June 2006; accepted 20 June 2006

Available online 20 July 2006

\begin{abstract}
Microarrays were developed to profile the level of proteins associated with calcium regulation in sarcoplasmic reticulum (SR) isolated from porcine Longissimus muscle. The microarrays consisted of SR preparations printed onto to glass slides and probed with monoclonal antibodies to 7 target proteins. Proteins investigated included: ryanodine receptor, (RyR), dihydropyridine receptor, (DHPR), triadin (TRI), calsequestrin (CSQ), $90 \mathrm{kDa}$ junctional protein (JSR90), and fast-twitch and slow-twitch SR calcium ATPases (SERCA1 and SERCA2). Signal from a fluorescentlylabeled detection antibody was measured and quantitated using a slide reader. The microarray developed was also employed to profile Longissimus muscle SR proteins from halothane genotyped animals. Significant $(P<0.05)$ reductions in levels of several proteins were found including: RyR, CSQ, TRI, DHPR and SERCA2 in SR samples from halothane positive animals. The results illustrate the potential of microarrays as a tool for profiling SR proteins and aiding investigations of calcium regulation.
\end{abstract}

(C) 2006 Elsevier B.V. All rights reserved.

Keywords: Protein microarray; Sarcoplasmic reticulum; Skeletal muscle; Protein profiling; Calcium regulation

Protein microarray represents a new proteomic technology that is rapidly gaining interest because of its ability to facilitate a variety of investigations including protein profiling and protein-protein interaction [1-4]. Protein and DNA microarrays are similar in that they require small amounts of sample. Typically, 1-10 ng of target molecules (protein or peptide) are printed in an array onto glass slides containing nitrocellulose pads or an activated surface. Printed proteins can then be probed with labeled antibodies or ligands. Microarrays require low reagent volumes $(\mu \mathrm{L})$ and have short processing times. These attributes conserve expensive and/or limited reagents and facilitate high sample throughput applications. Additionally, several arrays can be printed onto a single slide offering the capability of multiplexed analyses.

Detection of the desired component is accomplished by using fluorescently labeled probes. High sensitivity detection is achieved in protein microarrays through the use of laserinduced excitation employed by most slide readers. Several studies have affirmed the sensitivity of microarrays. A

\footnotetext{
* Corresponding author. Tel.: +1 402472 2827; fax: +1 4024721693 .
}

E-mail address: mzeece@unl.edu (M.G. Zeece). comparison of conventional and microarray based ELISA, found the microarray to be 4-fold more sensitive for the detection of autoimmune antibodies [5]. Greater detection sensitivity is possible in microarrays using signal amplification methods such as tyramide signal amplification (TSA), rolling circle amplification (RCA), or quantum dots (Qdots) [6-8].

Protein microarrays show promise as a tool to characterize the compliment of proteins in cells and tissues. A cell's proteome is constantly being modified by extrinsic and intrinsic factors. Growth, environmental change, and pathogenesis are but a few examples of the many influences resulting in changes to protein expression and protein post-translational modification. A variety of analyses are possible for proteome characterization using protein microarray approaches including: ELISA-based assay, protein-protein interaction investigation, and enzymatic activity assay [1-3]. However, one of the more interesting innovations for microarray analysis is reverse phase microarray (RPMA). RPMA analysis involves immobilizing of complex protein samples onto the slide (typically nitrocellulose pads) followed by probing with fluorescently labeled antibody. Samples are usually prepared as total extracts or cell lysates with denaturing methods similar to those used for 2- 
dimensional electrophoresis. Recent refinements in the sensitivity of signal detection (TSA, Qdots) have enabled measurement of low abundance proteins in heterogenous samples. RPMAs are being used to unravel the complexities signaling pathways that result in a cascade of events $[3,4]$. RPMAs have been used for profiling phosphorylated proteins associated with ovarian $[9,10]$ and prostrate $[11,12]$ cancers. It is hoped that the analysis capability provided by RPMAs will contribute significantly to the ability to diagnose and treat diseases.

The capabilities of microarray analysis also show promise for addressing other areas of research as well. Investigation of calcium regulation in muscle is one example where microarray analysis will potentially be of benefit. The SR is a membrane organelle that functions in the regulation of intracellular calcium concentration $[13,14]$. Abnormal calcium regulation has been linked to diseases such as malignant hyperthermia, myocardial failure, and muscular dystrophy. A mutation $(\mathrm{R} 615 \rightarrow \mathrm{C})$ in RyR protein is thought to be a primary cause of malignant hyperthermia [15]. This mutation is often referred to as the halothane (Hal) gene because it is possible for individuals with this defect to experience malignant hyperthermia triggered by administration of the anesthetic, halothane. Since this significant discovery, numerous other mutations in RyR have been reported [16]. Additionally, altered levels of calcium regulatory proteins in the SR occur in response to pathophysiological conditions. Studies employing immunoblotting found lower levels of RyR and DHPR proteins in malignant hyperthermia susceptible porcine Longissimus muscle [17], reduced level of calcium pump in failing myocardium $[18,19]$ and reduced level RyR isoform expression in smooth muscle of dystrophic mice [20]. These studies and others have demonstrated the need for methods to accurately profile SR proteins.

The goal of this work was to develop protein microarrays for the purpose of profiling the level of SR proteins important to calcium regulation. Proteins selected for examination in this study include: RyR, DHPR, CSQ, TRI, and junctional sarcoplasmic reticulum protein (JSR 90). In addition, calcium ATPase enzymes (SERCA1 and SERCA2) were also selected for screening. Specifically, a reverse phase type of microarray was developed for profiling these proteins in SR preparations. Data from these arrays were then assessed for potential relationship between the microarray determined SR protein profile and halothane genotyped animals.

Materials used in these experiments included: Precast polyacrylamide gels, polyvinylidene flouride (PVDF) membrane, blotting and electrophoresis materials were obtained from Bio-Rad (Hercules, CA). Monoclonal antibodies for the following proteins were purchased from Affinity BioReagents (Golden, CO): MA3-921, anti-dihydropyridine receptor alpha-2 subunit from rabbit skeletal muscle; MA3-933, junctional sarcoplasmic reticulum protein $(90 \mathrm{kDa})$ from rabbit skeletal muscle; MA3-913, calsequestrin from rabbit skeletal muscle, and MA3-912 SERCA1 ATPase from rabbit skeletal muscle; MA3-919, SERCA2 ATPase from canine cardiac muscle; and MA3-927, triadin from rabbit fast twitch skeletal muscle. Additionally, anti-ryanodine monoclonal antibody MAB3086 made from $\mathrm{C}$-terminal peptide of the receptor protein was purchased from Chemicon International (Temecula, CA). Secondary antibody (A90-116A Goat anti-mouse $\operatorname{IgG}$ ) was obtained from Bethyl labs (Montgomery, TX). Alexaflour 546 monoclonal antibody labeling kits and Sypro Ruby dye were obtained from Molecular Probes (Eugene, OR). Reagents for the BCA assay were obtained from Pierce (Rockford, IL). All water used for the preparation of reagents in this study was purified to $18 \mathrm{~m} \Omega$ using reverse osmosis.

The Longissimus muscle samples used in these experiments came from a set of 24 porcine animals that were previously halothane genotyped. These samples were a generous gift of Dr. Dave Gerrard at Purdue University (West Lafayette, IN). Individual samples were classified as halothane positive $\left(\mathrm{Hal}^{+}\right)$, halothane negative $\left(\mathrm{Hal}^{-}\right)$or halothane carrier $\left(\mathrm{Hal}^{\mathrm{c}}\right)$. The animals were genotyped using the method of O'Brien et al. [21]. All samples came from a population of adult animals. Longissimus muscle samples were taken immediately at death, frozen in liquid nitrogen, and stored at $-80{ }^{\circ} \mathrm{C}$ until used for SR isolation.

Sarcoplasmic reticulum membranes were isolated from porcine skeletal muscle using a variation of the method described by Saito et al, [22]. All steps of the procedure were performed at $1-2{ }^{\circ} \mathrm{C}$ unless stated otherwise. Briefly, the SR membrane fraction was isolated from frozen muscle by homogenizing $5 \mathrm{~g}$ of minced muscle for $90 \mathrm{~s}$ in a Warring blender in $25 \mathrm{~mL}$ of $300 \mathrm{mM}$ sucrose in $5 \mathrm{mM}$ imidazole $\mathrm{pH} 7.2$ containing $100 \mu \mathrm{m}$ E-64c and $1 \mathrm{mM}$ PMSF. After homogenization, the solution was adjusted to $10 \mathrm{mM}$ EGTA by addition of

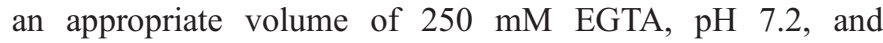
centrifuged at $9000 \times \mathrm{g}$ for $15 \mathrm{~min}$. The resulting supernatant was filtered through a nylon mesh strainer and centrifuged at $35,000 \mathrm{~g}$ for $90 \mathrm{~min}$ at $4{ }^{\circ} \mathrm{C}$. The pellet containing the SR fraction was taken up in a minimal volume of $5 \mathrm{mM}$ imidazole, $100 \mu \mathrm{M} \mathrm{E}-64 \mathrm{c}$ and $1 \mathrm{mM}$ PMSF and centrifuged on a $1.0 \mathrm{~mL}$ cushion of $30 \%$ sucrose, $5 \mathrm{mM}$ imidazole, $100 \mu \mathrm{M} \mathrm{E}-64 \mathrm{c}$ and $1 \mathrm{mM}$ PMSF at $130,000 \times g$ for $1 \mathrm{~h}$ The pellet from this spin was quick frozen in liquid nitrogen and stored at $-80{ }^{\circ} \mathrm{C}$.

SDS-PAGE was used to visualize the profile SR proteins in sample preparations and to screen the specificity of antibodies used in microarray analysis. Prior to electrophoresis, protein level in SR preparations was determined from an aliquot of sample solubilized in $0.2 \%$ SDS using the BCA (bicinchoninic acid) method (Pierce, Rockford, IL). Electrophoresis was performed on $4-15 \%$ polyacrylamide gels at $200 \mathrm{~V}$ constant voltage for $65 \mathrm{~min}$ or until the dye front migrated out of the gel. Proteins were visualized by staining with $0.1 \%$ Coomassie Brilliant Blue containing 10\% acetic acid, 50\% methanol and destained using 5\% acetic acid, 10\% methanol.

Immunblotting was performed on SDS-PAGE separated sample using a $4-15 \%$ gradient gel, containing a long single well of approximately $11 \mathrm{~cm}$ in width. Following electrophoretic separation, the gel width was trimmed to $8 \mathrm{~cm}$ and incubated in cathode Tris/CAPS transfer buffer $(60 \mathrm{mM}$ Tris, $40 \mathrm{mM}$ CAPS $\mathrm{pH} 9.4,0.1 \%$ SDS). The separation was then transferred electrophoretically to PVDF membrane. Anode transfer buffer contained $60 \mathrm{mM}$ Tris, $40 \mathrm{mM}$ CAPS pH 9.4, and $15 \%$ methanol. Transfer electrophoresis was performed in 
a semi-dry apparatus at $1.3 \mathrm{mAmps}$ per $\mathrm{cm}^{2}$ for $60 \mathrm{~min}$. The PVDF membrane was removed from the transfer unit and blocked overnight in 5\% Casein, $0.1 \%$ BSA dissolved Tris Buffered saline containing $0.1 \%$ Tween 20 (TBS-T). The membrane was then placed in an incubation manifold containing 16 channels. Each channel spanned the original separation from top to bottom and was approximately $0.5 \mathrm{~cm}$ in width. Channels were used for antibody incubation and had an internal volume of $200 \mu \mathrm{L}$. The manifold facilitated probing of a single membrane with all 7 antibodies used in this study. Two hundred $\mu \mathrm{L}$ of primary antibodies (diluted 1:100 with TBS-T for RyR, DHPR, CSQ, Tri and JSR90) were incubated per channel with the membrane. Antibodies for SERCA 1 and 2 were diluted 1:500 in TBS-T. Incubation with primary antibodies was performed for $2 \mathrm{~h}$ at $20{ }^{\circ} \mathrm{C}$. The membrane was removed from the manifold, washed several times and incubated for $1 \mathrm{~h}$ with Goat-anti-mouse IgG HRP conjugate (1:5000 dilution in TBS-T). Bound antibody was detected using a chemiluminescence system (SuperSignal West Dura, Pierce Rockford IL) and recorded on Kodak BioMax film.

Samples were prepared for microarray analysis by mixing an aliquot of the $0.2 \%$ SDS-solubilized SR fraction with an equal volume of printing buffer $\left(0.3 \mathrm{M} \mathrm{NaHPO}_{4} \mathrm{pH} 8.5,30 \%\right.$ glycerol, $0.2 \%$ trehalose and $0.01 \%$ Tween-20). Printing was performed using a Gene Machine Omnigrid 100 printer (GeneMachine, San Carlos, CA) using an ArrayIt (Santa Clara, CA) Stealth (SMP8xB) microspotting pin with a spot volume of $5 \mathrm{~nL}$ onto NHS (N-hydroxysuccinimide ester) functionalized slides (OptArrat, Denver, CO). SR proteins were printed at a final concentration of $0.5 \mathrm{ng} / \mathrm{nL}$. Each spot contained $2.5 \mathrm{ng}$ of protein and spots were spaced approximately $350 \mu \mathrm{m}$ apart. Arrays containing all 24 samples were printed. Each sample was printed 5 times for a total of 120 spots. Two replicate arrays (240 total spots) were printed per antibody probe. Printed arrays were incubated overnight at $20{ }^{\circ} \mathrm{C}$ at $60 \%$ humidity. The next day, unreacted sites on the slide were blocked by immersion in $50 \mathrm{mM}$ ethanolamine, $50 \mathrm{mM}$ borate, $\mathrm{pH}$ 8.0. Slides were then rinsed with $\mathrm{RO}$ water, dried with a stream of nitrogen and stored at $-20{ }^{\circ} \mathrm{C}$.

The aim of this microarray analysis was to measure differences in the composition of target proteins of the SR fraction. Thus, it was also necessary to assess the total amount of protein printed per spot. This was accomplished by staining duplicate arrays with a protein-detecting fluorescent dye (SYPRO Ruby). Briefly, $200 \mu \mathrm{L}$ of SYPRO Ruby was added to the slide and incubated for $5 \mathrm{~min}$ at $20{ }^{\circ} \mathrm{C}$. The slide was rinsed gently with $\mathrm{RO} \mathrm{H}_{2} \mathrm{O}$ and air-dried. The fluorescence intensity of protein spots was read at $543 \mathrm{~nm}$ excitation and $614 \mathrm{~nm}$ emission in a ScanArray 5000 reader (Perkin Elmer). This procedure enabled assessment of consistency of protein printing.

Incubations with antibodies were performed using silicone isolating masks (Grace BioLabs) that fit over the arrays. Adhesive backing on the mask kept solutions from mixing on the slide. Each slide typically contained two sets of arrays with corresponding incubation wells. Wells formed by the isolating mask had an internal volume of $250 \mu \mathrm{L}$. Individual arrays were incubated for $2 \mathrm{~h}$ with $200 \mu \mathrm{L}$ of the appropriate monoclonal antibody, diluted 1:100 in PBST. Following incubation, arrays were washed 3 times with PBST. Detection of bound monoclonal antibody was performed with goat anti-mouse polyclonal antibody conjugated to Alexa Fluor 546 (Molecular Probes). Briefly, labeling of detection antibodies was performed by mixing the dye (succinimidyl ester form) with $100 \mu \mathrm{g}$ of purified goat anti-mouse IgG antibody (Bethyl Labs). Labeled antibody was separated from free dye using a small $(1 \mathrm{~mL})$ size exclusion column. The efficiency of labeling was determined from the absorbance ratio (280 to $558 \mathrm{~nm}$ ). Using the extinction coefficient for the dye, a ratio of 2-3 dye per protein molecules was routinely obtained.

Detection of bound IgG in the array was performed by adding $200 \mu \mathrm{L}$ of fluorescently labeled antibody (diluted 1:1,000 with PBS-T) for each set of arrays. Arrays were then incubated for $1 \mathrm{~h}$ at $20{ }^{\circ} \mathrm{C}$. At the end of the incubation, arrays were rinsed 5 times with PBS-T. The adhesive backed mask was then carefully removed and the slide surface rinsed gently with RO $\mathrm{H}_{2} \mathrm{O}$. Slides were dried with a stream of nitrogen and analyzed using laser excitation at $543 \mathrm{~nm}$ with emission measured at $570 \mathrm{~nm}$ in a ScanArray 5000 instrument. The ScanArray instrument generates TIFF and Bitmap images for quantification and visual evaluation, respectively. Images were analyzed using ImaGene (BioDiscovery Inc., El Segundo, CA) version 5.0. Imagene software was used to define and quantify the spot area and intensity. Spots that were abnormal in size or shape were omitted from the analysis. Signal intensity from all valid spots was averaged and the standard error of the means calculated. Averaged signal intensities were also normalized for the amount of protein spotted. Normalized values were obtained by dividing averaged sample signal intensity by the averaged protein signal determined from corresponding SYPRO-stained arrays. The resulting data (expressed as normalized sample signal intensity) from 2 replicate arrays were averaged and used to examine differences between samples. A total of 24 animals representing halothane positive (4), negative (10) and heterozygote (10) (carrier) genotypes were investigated in this study. These data were analyzed using the One-way ANOVA function of SAS and significant differences were determined using Fishers Least Significant Difference [23].

Isolation of the SR-containing fraction from porcine skeletal muscle by differential sedimentation centrifugation was performed essentially as described by Saito et al, [22]. However, the isolation procedure used in here was halted after obtaining $130,000 \mathrm{~g}$ (microsomal) pellets. It was possible to routinely obtain 1-2 mg of SR preparation for microarray analysis from $5 \mathrm{~g}$ muscle samples.

The profile of SR proteins obtained by SDS-PAGE is shown in lane a of Fig. 1A. This lane contains a separation of a halothane negative sample on a $4-15 \%$ gradient gel. Protein bands in this separation range in size from $630 \mathrm{kDa}$ to about $10 \mathrm{kDa}$. The highest $M_{\mathrm{r}}$ bands represent a minor portion of the sample and have an approximate $M_{\mathrm{r}}$ of $630 \mathrm{kDa}$ and $385 \mathrm{kDa}$ (a doublet). Bands with $M_{\mathrm{r}}$ ranging from $175 \mathrm{kDa}$ to $10 \mathrm{kDa}$ represent a majority of proteins found in this fraction. Specifically, SR 


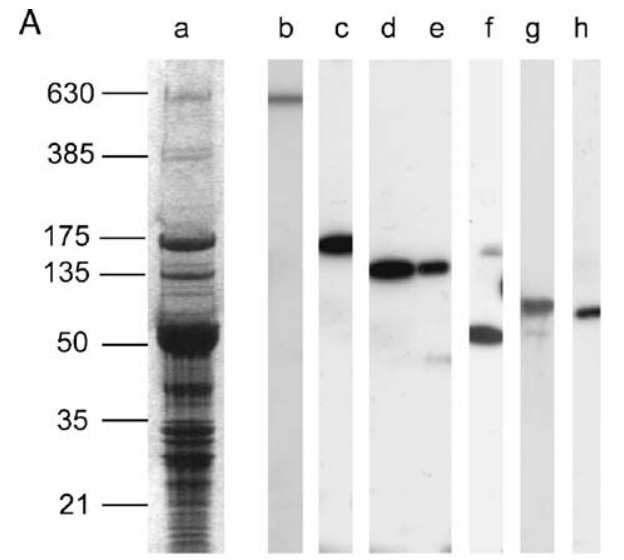

B

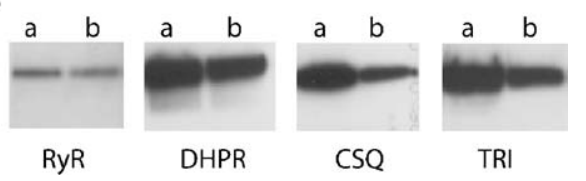

Fig. 1. SDS-PAGE and immunoblotting of SR preparation. (A) Forty $\mu \mathrm{g}$ of SR fraction from a halothane negative Longissimus muscle sample was separated on 4-15\% SDS-PAGE gel (lane a). $M_{\mathrm{r}}$ values are indicated to the left of this lane. Lanes $\mathrm{b}$-h contain immunoblots of the same sample probed with antibodies to: RyR (b), DHPR (c), SERCA1 (d), SERCA2 (e), CSQ (f), TRI (g), and JSR90 (h). (B) Identical loads of SR fraction from halothane negative (a) and positive (b) samples were separated on $4-15 \%$ SDS-PAGE gel and probed by immunoblotting with antibodies to: RyR, DHPR, CSQ, and TRI.

proteins found in bands ranging from 65 to $23 \mathrm{kDa}$ represent the dominant components. The protein profile observed in Fig. 1A (lane a) was similar to that reported by others for porcine skeletal muscle SR preparations [17,24]. SDS-PAGE separations of SR fractions presented by these authors showed fewer bands, especially in the $30-60 \mathrm{kDa}$ range. This difference may be due to the additional sample fractionation (sucrose density gradients) that was employed prior electrophoretic separation $[17,24]$.

The specificity of antibodies used in this study was confirmed by immunoblotting the same halothane negative SR protein sample (Fig. 1A. lanes b through h). Anti-RyR monoclonal antibody (MAB3086) was observed to label a single band at about $630 \mathrm{kDa}$ (Fig. 1A, lane b), but not the $385 \mathrm{kDa}$ doublet observed in the protein separation (lane a). The $385 \mathrm{kDa}$ doublet may represent RyR degradation products that were not recognized by the antibody and also not measured in the subsequent microarray analysis. Monoclonal antibody MA3-921 against DHPR alpha 2 subunit labeled a single band with $M_{\mathrm{r}}$ of approximately $165 \mathrm{kDa}$ (lane c). The $M_{\mathrm{r}}$ is higher than the expected value of $143 \mathrm{kDa}[25,26]$. However, the size reported here may have resulted from the gradient gel system which compresses the mid range separation in favor of higher $M_{\mathrm{r}}$ resolution. Lanes $\mathrm{d}$ and e show that antibodies against SERCA 1 (MA3-912) and SERCA2 (MA3 919) recognize single bands in their respective lanes. The relative intensity of the bands in lanes $d$ and e reflect the differences in the level of these ATPases in Longissimus muscle. SERCA1 ATPase level is greater than SERCA2 ATPase in fast twitch muscle [27]. Lane $f$ shows that monoclonal antibody (MA3-913) against
CSQ resulted in a major immunoreactive band with $M_{\mathrm{r}}$ of about $65 \mathrm{kDa}$. Some additional staining products can be seen in the regions above the major band. However, these products represent a small amount of lateral antibody leakage that occurred during incubation of the PVDF membrane in the manifold. Lane g shows a major immunoreactive band resulting from incubation with monoclonal antibody (MA3-927) against TRI. The major band corresponds to a $M_{\mathrm{r}}$ of $95 \mathrm{kDa}$. A much less intense immunoreactive band, likely representing a degradation product of TRI, can be seen just below the $95 \mathrm{kDa}$ band. Finally, lane h shows a single reactive product with monoclonal antibody (MA3-933) against Junctional SR $(90 \mathrm{kDa})$ protein. Additional immunoblotting was performed on SR preparations from a single representative halothane negative (a) and positive (b) sample using antibodies against RyR, DHPR, CSQ and TRI (Fig. 1B). Noticeably reduced immunoreactive bands were observed in the halothane positive SR sample for DHPR, CSQ, and TRI proteins. Only slight a difference was observed in the amount of immunoreactive product for RyR between halothane positive and negative sample.

The microarray approach used in this work was similar to the RPMA mode demonstrated others [3,4]. However, our SR protein preparations were printed at a constant level onto a glass surface. The substrate used in these arrays contained an activated (NHS) surface by which sample proteins were covalently attached. In contrast, nitrocellulose used for most RPMA applications retains proteins by electrostatic charge. Both methods have been shown to work well in capturing proteins. Nitrocellulose slides can provide greater protein binding capacity, but may also contribute to decreased signal to noise ratios due to non-specific binding of detection antibody. Numerous conditions were investigated to optimize printing of SR proteins on glass microarrays. Inclusion of the detergent SDS was necessary to solubilize SR proteins. However SDS greatly reduced the surface tension of the solution resulting in unwanted spreading of the spot. The problem was compensated for by the addition of glycerol to the print buffer. In addition to improving viscosity, glycerol served as a humectant and helped to inhibit desiccation of the printed proteins. SYPRO staining of arrays was essential to these microarray analyses in that it enabled correction for small differences in the amount of SR protein printed.

All primary antibodies used in this study were monoclonal. The dilution of each primary antibody was examined individually. It was found that $200 \mu \mathrm{L}$ of a 1:100 dilution provided substantial excess antibody relative to the amount of protein printed in an array and was therefore used for all arrays. Fluorescently labeled goat anti-mouse $\operatorname{IgG}$ antibody was used to detect monoclonal antibodies bound to protein in the spot. In dilution experiments, $200 \mu \mathrm{L}$ of a 1:1000 dilution was found to be the greatest dilution of labeled antibody that would provide sufficient detection of the bound proteinspecific monoclonals in printed arrays. Fluorescence signal from the detection antibody was laser-induced and the signal to noise ratio was 2.0 or greater for all antibody arrays. Nonspecific binding of detection antibody was tested by adding 
the same dilution to arrays in which primary antibody was absent.

An image of the resulting microarray is shown in Fig. 2. This figure contains a composite array image together with corresponding control (incubations without primary antibody). The control indicates a very low level of non-specific binding by the detection antibody. Each sub-array consists of 5 halothane negative SR samples printed 5 times per sample, for a total of 25 spots. Spot signal intensity (low to high) is represented in the array image by a change in color from light blue to orange-red. Overall, the relative intensities of these arrays show that SERCA1 and JSR 90 have the highest and lowest signal intensities, respectively. Signals from the other target proteins (RyR, DHPR, CSQ, SERCA2 and TRI) fall within this range of intensities. Quantitative assessment of microarrays was achieved using the Imagene software followed by statistical analyses.

Analytical arrays were constructed containing all 24 samples, printed as 5 replicate spots per sample (a total of 120 spots per array). Variation between replicate arrays was determined by calculating the RSD values from the adjusted signal intensities of 5 replicate spots printed per sample. RSD values were then averaged by genotype (halothane positive, negative or carrier) and the results shown in Fig. 3. RSD values for individual target proteins ranged from $9 \%$ to $30 \%$ within both replicate slides. The highest level of RSD variation within slides occurred for proteins present in the lowest amount (JSR90). Overall there was good agreement between the slides. It is of interest to note that lowest level of RSD variation between slides was observed for the halothane positive genotype samples. It was found that all 7 target protein RSD values were in good agreement between slides for this genotype.

Data from the microarray analysis for each protein were next examined for differences between animals representing the three genotypes (halothane positive, negative and carrier) (Table 1). Significant differences $(P<0.05)$ were found in the level of several SR proteins predominantly between halothane positive and negative samples (Table 1). Specifically, a 43\% reduction in the level of RyR1 and a 37\% reduction DHPR $\alpha 2$ subunit were found in SR from Hal positive samples. In addition, significantly decreased levels of CSQ (44\%), SERCA2 $(24 \%)$, and TRI $(40 \%)$ were found in SR from halothane positive samples. This result is in agreement with the reduction in the level of DHPR, CSQ and TRI proteins for halothane positive SR samples shown in our immunoblot results (Fig. 1B). However, the slight difference observed in the level of RyR immunoreactive band between halothane positive and negative SR samples was in contrast to the significantly lower level found for this protein by the microarray analysis. This may have resulted from sample variability. The immunoblot result was obtained from single halothane positive and negative samples, whereas the microarray analysis compared 4 positive to 10 negative samples. SR samples from heterozygous (halothane carrier) animals did not show significant differences in the level of most proteins investigated. The only significant difference was found for TRI with the halothane positive sample (Table 1). TRI level was approximately $35 \%$ lower in the halothane positive sample. This may represent an interesting result since a reduction in TRI might equate to lower calcium binding (storage) capacity in malignant hyperthermia susceptible animals.

Results presented here regarding expression of major calcium regulatory proteins are in agreement with other investigations suggesting that decreased levels of key proteins may be a factor in calcium regulation abnormalities. Significant reductions in RyR (38\%) and DHPR (55\%) proteins were found in the SR of Longissimus muscle of malignant hyperthermia susceptible porcine animals using immunoblotting methods [17]. Reduction in RyR protein was significant for both

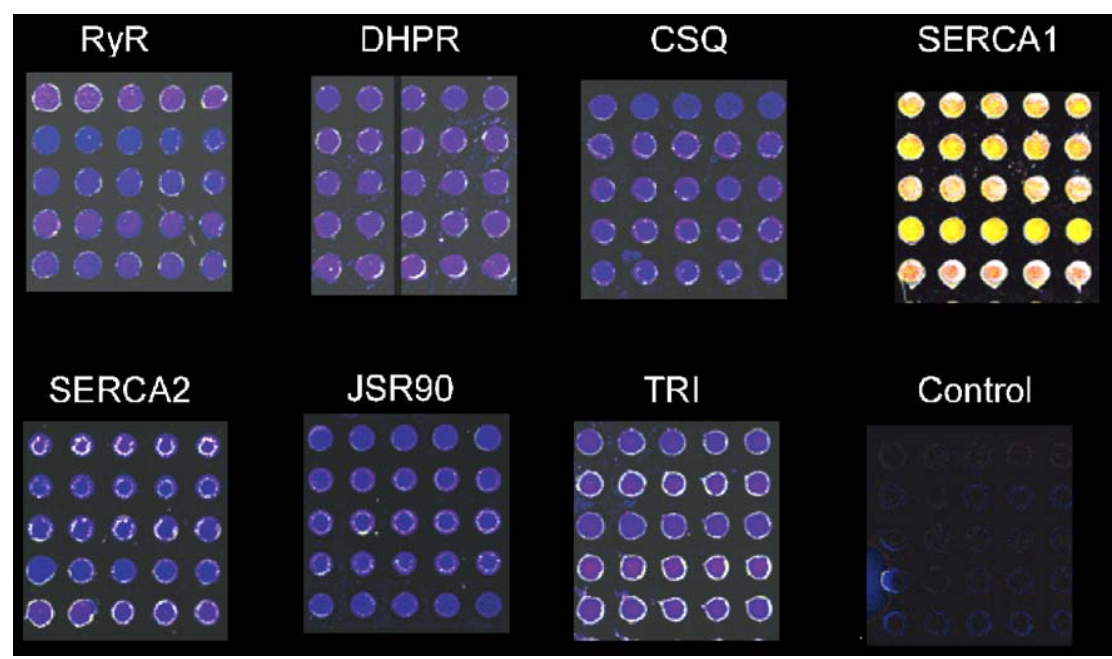

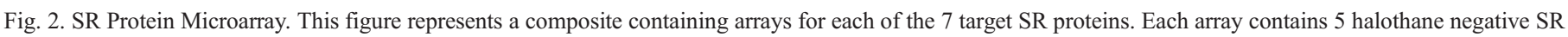

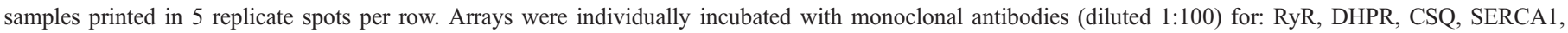

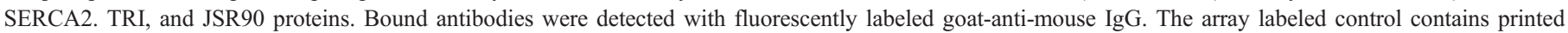

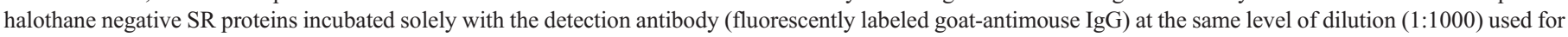
detection of the monoclonals. 

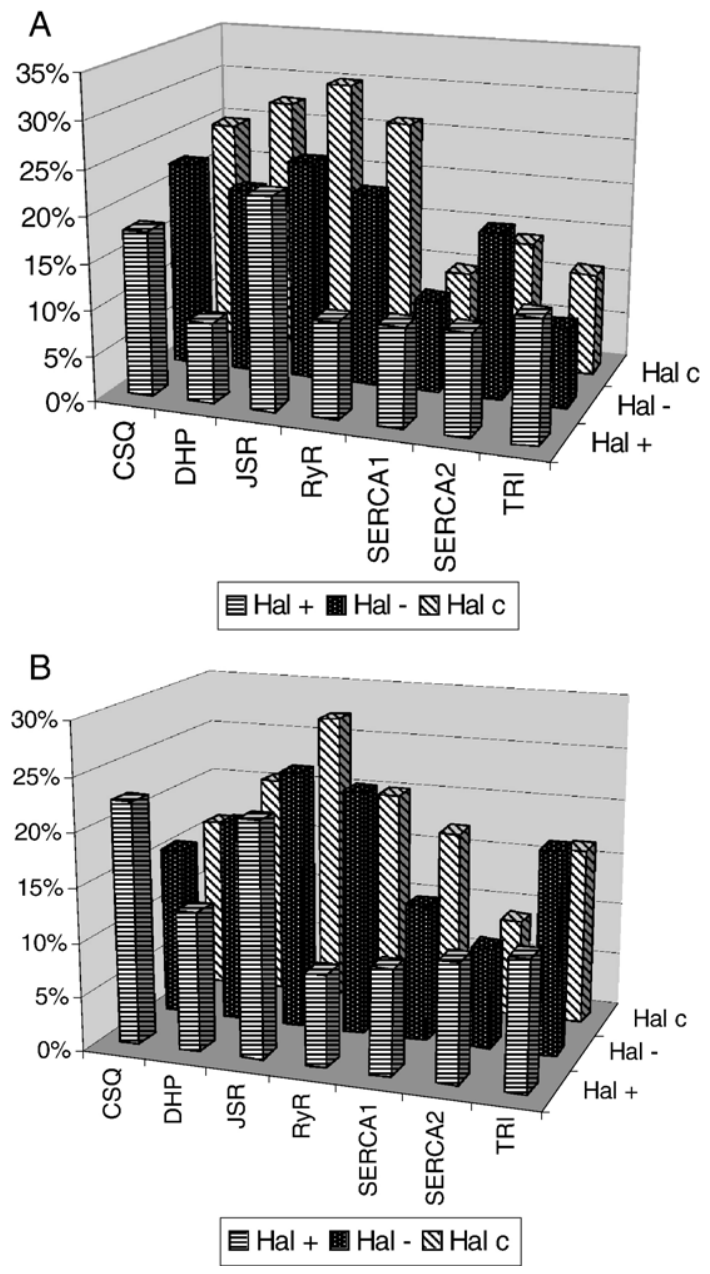

Fig. 3. Replicate Microarray RSD. RSD values were calculated from normalized signal intensities of the 5 spots printed per sample. RSD values for each target protein (CSQ, RyR, JSR90, DHPR, SERCA1, SERCA2, and TRI) were then averaged by genotype; halothane positive $(+)$, negative $(-)$ or carrier(c). RSD values for the replicate arrays are shown as bar graphs in figures A and B.

homozygote and heterozyogte (carrier) RyR genotypes. Lower levels of both RyR and DHRP protein was suggested as a cause for altered calcium homeostasis in malignant hyperthermia susceptible animals [17]. Additionally, a study conducted by immunoblotting of SR proteins in human patients with failing dilated cardiomyopathy found no change in proteins associated with calcium binding and release (CSQ and RyR) compared to non-failing controls [19]. However, this study did find a significant decrease in the level of SR ATPase in failing hearts. The authors suggested that elevated sarcoplasmic level in failing heart tissue may have resulted from decreased calcium pump function.

In contrast, expression of SR proteins associated with calcium regulation was not altered in human muscle susceptible to malignant hyperthermia [26]. This study used immunoblotting of biopsy samples taken from vastus lateralis muscle. The authors demonstrated little or no observable difference in the immunoreactive bands for several SR proteins including: RyR, DHPR ( $\alpha 1 \mathrm{~s}$ and $\alpha 2)$, CSQ, Junctin, SERCA1, and SERCA2. The report did demonstrate a halothane-induced oligomeriza- tion of RyR and SERCA1 by electrophoretic gel shift assay in SR preparations isolated from malignant hyperthermia susceptible individuals. Explanations for the lack of difference in the profile of SR proteins in this study compared to our results are not readily apparent. However, Glover et al. [26] selected samples for their study based on an in-vitro contracture test rather than the genotyping approach used to select samples in our work. Additionally, Glover et al. [26] drew their conclusions from immunoblotting of a small number of representative samples of normal and malignant hyperthermia susceptible individuals. We experienced similar differences between immunoblots of single RyR halothane positive/negative samples and microarray data (Fig. 1B/Table 1).

Abnormalities in calcium regulation are linked to adverse health consequences. Mutations in the calcium channel protein RyR likely represent a major portion of the causation of malignant hyperthermia in humans and the analogous condition in porcine animals. However, there is evidence that alterations in the profile calcium regulatory proteins (DHPR), or binding (CSQ and SERCA1 and 2) proteins may represent contributing factors to the disease state. Cardiomyopathy and muscular dystrophy are conditions that result in altered calcium regulatory protein profile $[19,20,28]$. These studies and others have demonstrated the need for methods to accurately profile SR proteins.

The results presented here show that microarrays represent a viable and advantageous technology to profile SR proteins. A comprehensive SR profile may include probes for RyR, DHPR, CSQ, TRI, JSR90, Junctin, SERCA1 and 2, Calsequstrin-like proteins, Calreticulin and isoforms or subunits of many of the above. Additionally, valuable information may be derived from sarcoplasmic calcium modulating proteins such as calmodulin and FKBP12. Microarray technology would enable quantitative assessment of multiple targets. Combined protein microarray and genomic data represent a promising way forward to determine the underlying biology of calcium regulation abnormalities and provide appropriate diagnostic tools. Future

Table 1

Microarray analysis summary of SR proteins in halothane genotyped animals

\begin{tabular}{lccr}
\hline Protein & \multicolumn{3}{l}{ Genotype } \\
\cline { 2 - 4 } & $\mathrm{Hal}^{-}(n=10)$ & $\mathrm{Hal}^{\mathrm{c}}(n=10)$ & $\mathrm{Hal}^{+}(n=4)$ \\
\hline CSQ & $4.00 \pm 0.37^{\mathrm{a}}$ & $3.17 \pm 0.26^{\mathrm{a}, \mathrm{b}}$ & $2.24 \pm 0.42^{\mathrm{b}}$ \\
DHPR & $4.85 \pm 0.44^{\mathrm{a}}$ & $4.30 \pm 0.21^{\mathrm{a}, \mathrm{b}}$ & $3.05 \pm 0.29^{\mathrm{b}}$ \\
JSR90 & $1.63 \pm 0.15^{\mathrm{a}}$ & $1.90 \pm .033^{\mathrm{a}}$ & $1.10 \pm 0.24^{\mathrm{a}}$ \\
RyR & $4.76 \pm 0.48^{\mathrm{a}}$ & $3.77 \pm 0.49^{\mathrm{a}, \mathrm{b}}$ & $2.70 \pm 0.43^{\mathrm{b}}$ \\
SERCA1 & $11.67 \pm 0.85^{\mathrm{a}}$ & $11.03 \pm 0.89^{\mathrm{a}}$ & $11.90 \pm 1.02^{\mathrm{a}}$ \\
SERCA2 & $2.93 \pm 0.17^{\mathrm{a}}$ & $2.55 \pm 0.14^{\mathrm{a}, \mathrm{b}}$ & $2.23 \pm 0.24^{\mathrm{b}}$ \\
TRI & $4.01 \pm 0.33^{\mathrm{a}}$ & $3.74 \pm 0.26^{\mathrm{a}}$ & $2.40 \pm 0.37^{\mathrm{b}}$ \\
\hline
\end{tabular}

SR preparations from Longissimus muscle of 24 animals genotyped as halothane positive $(+)$, negative $(-)$ or carrier(c) were profiled by the microarray procedure described using monoclonal antibodies specific for RyR, DHPR, CQS, SERCA1, SERCA2, TRI, and JSR90. The number (n) of animals in each group was: 4 positive, 10 negative, and 10 carrier. Values in the table were obtained from an average of two arrays in which each sample was printed 5 times. Each value is represented as normalized signal intensity mean $\pm \mathrm{SEM}$. Superscripts $(a, b, c)$ were used to denote statistical differences. Values with differing superscripts denote significant difference $(P<0.05)$ between means. 
development of microarray analysis for SR protein profiling would benefit from the ability to detect these targets in printed whole extracts. It is likely that nitrocellulose substrates in combination with signal amplification methods would enable accomplishment of this task.

\section{Acknowledgements}

This work was supported by USDA grant \#16-044 and by the University of Nebraska Agricultural Research Division, Innovative Research Grants program (Journal Series Number 15016).

\section{References}

[1] D. Figeys, Adapting arrays and lab-on-a-chip technology for proteomics, Proteomics 2 (2002) 373-382.

[2] S.A. Sieber, T.S. Mondala, S.R. Head, B.F. Cravatt, Microarray platform for profiling enzyme activities in complex proteomes, J. Am. Chem. Soc. 12 (2004) 15640-15641.

[3] V. Espina, A.L. Mehta, M.E. Winters, V. Calvert, J. Wulfkuhe, E.F. Petricoin III, L.A. Lioata, Protein microarrays: molecular profiling technologies for clinical specimens, Proteomics 3 (2003) 2091-2100.

[4] S. Chan, J. Ermann, L. Su, C.G. Fathman, P.J. Utz, Protein microarrays for multiplex analysis of signal transduction pathways, Nat. Med. 10 (2004) 1390-1396.

[5] W.H. Robinson, C. DiGennaro, W. Hueber, B.B. Haab, M. Kamachi, E.K. Dean, S. Fournell, D. Fong, M.C. Genovese, H.E. Neuman, D. Vegvar, K. Skriner, D.L. Hirschberg, R.J. Morris, S. Muller, G.J. Pruijn, W.J. van Venrooij, J.S. Smolen, P.O. Brown, L. Steinman, P.J. Utz, Autoantigen microarrays for multiplex characterization of auto antibody responses, Nat. Med. 8 (2002) 295-301.

[6] B.S. Schweitzer, J. Wiltshire, S. Lambret, K. O’Malley, K. Kukamskis, Z. Zhu, S.F. Kingsmore, P.M. Lizardi, D.C. Ward, Immunoassays with rolling circle DNA amplification: a versatile platform for ultrasensitive antigen detection, Proc. Natl. Acad. Sci. U. S. A. 97 (2000) 10113-10119.

[7] L. Bacarese-Hamilton, L. Mezzasoma, V. Ingham, A. Ardizzoni, R. Rossi, F. Bistoni, A. Crisanti, Detection of allergen-specific IgE on microarrays by use of signal amplification techniques, Clin. Chem. 48 (2002) 1367-1370.

[8] D. Geho, N. Lahar, P. Gurnani, M. Huebschman, P. Herrmann, A. Espina, A. Shi, J.D. Wulfkuhle, H. Garner, E.F. Petricon III, L.A. Liotta, K. Rosenblatt, Bioconjug. Chem. 16 (2005) 559-566.

[9] J.D. Wulfkuhle, J.A. Aquino, V.S. Calvert, D.A. Fishman, G. Coukos, L.A. Liotta, E.F. Petricon III, Signal pathway profiling of ovarin cancer from human tissue specimens using reverse-phase protein microarrays, Proteomics 3 (2003) 2085-2090.

[10] K.M. Sheehan, V.S. Calvert, E.W. Kays, Y. Lu, D. Fishman, V. Espina, J. Aquino, R. Speer, R. Araujo, G.B. Mills, L. Lioatta, E.F. Petricon III, J.D. Wulfkuhle, Use of reverse phase protein microarrays and reference standard development for molecular network analysis of metastatic ovarian carcinoma, Mol. Cell. Proteomics 4 (2005) 346-355.

[11] K. Bouwman, J. Qiu, H. Zhou, M. Schotanus, L.A. Mangold, R. Vogt, E. Eirandson, J. Trinkle, A.W. Partin, D. Misek, G.S. Omen, B.B. Haab, S. Hanash, Microarray of tumor cell derived proteins uncover a distinct pattern of prostate cancer serum immunoreactivity, Proteomics 3 (2003) $2200-2207$.
[12] R.L. Grubb, V.S. Calvert, J.D. Wulkuhle, C.P. Paweletz, W.M. Linehan, J.L. Phillips, R. Chuaqui, A. Valasco, M. Emmert-Buck, L.A. Liotta, E.F. Petricoin III, Signal pathway profiling of prostate cancer using reverse phase protein arrays, Proteomics 3 (2003) 2142-2146.

[13] C. Franzini-Armstrong, The sarcoplasmic reticulum and the control of muscle contraction, Fed. Am. Soc. Exp. Biol. J. 13 (1999) S266-S270 (Suppl.).

[14] C. Franzini-Armstrong, F. Protasi, Ryanodine receptors of striated muscles: a complex channel capable of multiple interactions, Physiol. Rev. 77 (1997) 699-729.

[15] J. Fuji, K. Otsu, F. Zorzato, S. De Long, V.K. Khanna, J.E. Weiler, P.J. O'Brien, D.H. MacLennan, Identification of a mutation in porcine ryanodine receptor associated with malignant hyperthermia, Science 253 (1991) 448-451.

[16] T.V. McCarthy, K.A. Quane, P.J. Lynch, Ryanodine receptor mutations in malignant hyperthermia and central core disease, Hum. Mut. 15 (2000) 410-417.

[17] J.R. Mickelson, J.M. Ervasti, L.A. Litterer, K.P. Campbell, C.F. Louis, Skeletal muscle junctional membrane protein content in pigs with different ryanodine receptor genotypes, Am. J. Physiol. 267 (1994) C282-C292.

[18] M. Arai, N.R. Alpert, D.H. MacLennan, P. Barton, M. Periasamy, Alterations in sarcoplasmic reticulum gene expression in human heart failure: a possible mechanism of alterations in systolic and diastolic properties of the failing myocardium, Circ. Res. 72 (1993) 463-469.

[19] M. Meyer, W. Schillinger, B. Pieske, C. Holubarsch, C. Heilmann, H. Posival, G. Kuwajima, K. Mikoshiba, H. Just, G. Hasenfus, et al., Alterations of sarcoplasmic reticulum proteins in failing human dilated cardiomyopathy, Circulation 92 (1995) 778-784.

[20] J.L. Morel, L. Rakotoarisoa, L.H. Jeyakumar, S. Fleischer, C. Mironneau, J. Mironneau, Decreased expression of ryanodine receptors alters calcium-induced calcium release mechanism in $\mathrm{mdx}$ mice duodenal myocytes, J. Biol. Chem. 279 (2004) 21287-21293.

[21] P.J. O'Brien, H. Shen, C.R. Cory, X. Zhang, Use of a DNA-based test for the mutation associated with porcine stress syndrome (malignant hyperthermia) in 10,000 breeding swine, J. Am. Vet. Med. Assoc. 203 (1993) 581-842.

[22] A. Saito, S. Seiler, S. Fleischer, Preparation and morphology of sarcoplasmic reticulum terminal cisternae from rabbit skeletal muscle, J. Cell Biol. 99 (1984) 875-885.

[23] SAS Institute. 1990. SAS/STAT User's Guide: Statistics. Version 6. 1st ed. SAS Institute Inc., Cary, NC.

[24] J.R. Mickelson, J.R. Ross, B.K. Reed, C.F. Lewis, Enhanced Ca-induced calcium release by isolated sarcoplasmic reticulum vesicles from malignant hyperthermia susceptible pig muscle, Biochim. Biophys. Acta 862 (1986) 318-328.

[25] H.B. Rasmussen, M.H.G. Moller, B.S. Knaus, S.P. Jensen, N.K. Olsen, Subcellular localization of the delayed rectifier K+channels KCNQ1 and ERG1 in the heart, Am. J. Heart Circ. Physiol. 286 (2004) H1300-H1309.

[26] L. Glover, J.J.A. Heffron, K. Ohlendieck, Increased sensitivity of the ryanodine receptor to halothane-induced oligomerization in malignant hyperthermia-susceptible human skeletal muscle, J. Appl. Physiol. 96 (2004) 11-18

[27] L. Glover, S. Quinn, M. Ryan, D. Pette, K. Ohlendieck, Supramolecular calsequestrin complex, Eur. J. Biochem. 269 (2002) 4607-4616.

[28] K. Culligan, N. Banville, P. Dowling, K. Ohlendieck, Drastic reduction of calsequestrin-like proteins and impaired calcium binding in dystrophic mdx muscle, J. Appl. Physiol. 92 (2002) 435-445. 